\begin{tabular}{|l|l|l|l|l|l|}
\hline J. Tek. Ling & Vol.10 & No.3 & Hal. 277 - 290 & Jakarta, Sept 2009 & ISSN 1441-318X \\
\hline
\end{tabular}

\title{
PENGEMBANGAN PERANGKAT LUNAK DATABASE MONITORING KINERJA TPA
}

\author{
Heru Dwi Wahyono \\ Peneliti di Pusat Teknologi Lingkungan \\ Badan Pengkajian dan Penerapan Teknologi
}

\begin{abstract}
The increasing number of resident in an area impact to the increasing number of domestic waste produced by that area. The amount of existing landfill waste is not enough to accommodate all waste. This is the reason why the researchers need to develop a landfill waste with good performance. Good performance landfill can treat waste quickly and does not contaminate the environment. Methan gas produced by the landfill waste can be used as alternatif energy resources. To improve the performance of landfill waste, the waste management in landfill waste need to be monitored. The landfill waste monitoring carried out on quality of leacate, volume and concentration of gas, and some other parameters. To facilitate the monitoring process should be developed database software for landfill waste performance monitoring. With this software the data is managed in such a way so that it can be called back quickly and easily and can be displayed in various forms of landfill performance analysis reports.
\end{abstract}

Key words : Tempat Pemrosesan Akhir Sampah, Pengelolaan Sampah, Database Monitoring Kinerja TPA

\section{PENDAHLUAN}

\subsection{Latar Belakang}

Penelitian tentang Tempat Pembuangan Akhir (TPA) sampah yang memiliki kinerja yang baik sangat dibutuhkan untuk mengentaskan permasalahan sampah di kota-kota besar di Indonesia. Selain lindi TPA juga menghasilkan gas buangan lain berupa metan dalam jumlah yang banyak. Gas ini dengan penanganan tertentu dapat digunakan untuk sumber energi alternatif. Untuk mengoptimalkan penggunaan TPA yang rata-rata hanya ada satu di kota-kota besar dan metropolitan, maka perlu dipantau kinerjanya.

Kegiatan pemantauan dilaku-kan untuk mengetahui data parameter gas, temperatur, kelembaban dan debit gas di setiap lapisan sampah yang ada di TPA.

Pengelolaan data hasil pemantauan baik yang dilakukan secara manual ataupun secara otomatis menggunakan suatu sistem online monitoring sangat memerlukan sistem pengelolaan data terstruktur yang mampu mengelola data sedemikian rupa sehingga data dapat disajikan kembali dalam berbagai bentuk laporan. Hasil pengumpulan data dapat dianalisa untuk proses pengambilan kebijakan tertentu oleh manajemen.

\subsection{Tinjauan Pustaka}

\section{I.2.1. Kebijakan Pemerintah Mengenai Pengelolaan Sampah}

Keseriusan pemerintah baik pusat maupun daerah dalam menangani masalah persampahan telah dituangkan ke dalam 
beberapa peraturan tentang persampahan. Kebijakan pemerintah pusat terhadap masalah pengelolaan sampah telah direvisi dengan keluarnya Undang-Undang Nomor 18 Tahun 2008 Tentang Pengelolaan Sampah. Di dalamnya telah diatur tugas dan wewenang pemerrintah dalam pengelolaan sampah ${ }^{1)}$.

Tugas dan kewenangan pemerintah baik pusat maupun daerah yang berkaitan dengan peningkatan kinerja TPA telah diuraikan dalam UU No. 18 Tahun 2008 yakni ${ }^{1)}$ :

- Melakukan penelitian, pengembangan teknologi pengurangan, dan penanganan sampah.

- Melaksanakan pengelolaan sampah dan memfasilitasi penyediaan prasarana dan sarana pengelolaan sampah.

- Melakukan pemantauan dan evaluasi secara berkala setiap 6 bulan selama 20 tahun terhadap tempat pemrosesan akhir sampah dengan sistem pembuangan terbuka yang telah ditutup.

\section{I.2.2. Pengelolaan Gas TPA}

Gas yang dihasilkan oleh sebuah TPA merupakan gas-gas yang bersifat berbahaya, yakni beracun dan mudah terbakar. Sejak dideklarasikan Protokol Tokyo pada tahun 1997 dan kesadaran dunia untuk turut mengendalikan pemanasan global, maka gas-gas yang dihasilkan oleh sebuah TPA merupakan gas-gas yang termasuk dalam Green House Gases (CHG) atau Gas Rumah Kaca (GRK). Gas-gas ini memiliki kontribusi yang besar dalam proses perubahan iklim pemanasan global. ${ }^{2)}$

Sulitnya menurunkan emisi GRK melalui pengelolaan gas di TPAmenyebabkan diciptakannya Clean Development Mechanism (CDM) yang bertujuan untuk memanfaatkan gas-gas yang dihasilkan oleh TPA menjadi sumber energi alternatif.
Kegiatan ini disebut sebagai Landfill Gas to Energy (LFGE). Adapun gas yang dihasilkan oleh sebuah TPA umumnya terdiri dari gas $\mathrm{CH}_{4}, \mathrm{CO}_{2}, \mathrm{H}_{2} \mathrm{~S}$, dan $\mathrm{O}^{2}$ dengan komposisi yang berbeda-beda ${ }^{2)}$.

\section{I.2.3. Konsep Pengembangan Sistem}

Di dalam ilmu informatika dan komputer, pengembangan sebuah perangkat lunak, secara konseptual memiliki suatu evolusi (Software Evolutaion), yang terdiri dari rangkaian aktivitas yang akan terjadi selama proses pengembangan dan pemeliharaan sistem software tersebut. ${ }^{3)}$ Aktifitas tersebut antara lain :

\section{- $\quad$ System Initiation/Adoption \\ - Requirement Analysis and Specification \\ - Functional Specification or Prototyping \\ - Partition and Selection (Build/Buy/ Reuse) \\ - Architectural Configuration Specification \\ - Detailed Component Design Specification \\ - Component Implementation and Debugging \\ - $\quad$ Software Integration and Testing \\ - Documentation and System Delivery \\ - $\quad$ Training and Use \\ - Software Maintenance}

Di dalam software evolution yang terdiri serangkain aktivitas di atas menyajikan berbagai macam metodologi berupa model daur hidup perangkat lunak (Software Life Cycle) ${ }^{3)}$, yaitu :

- $\quad$ Model Build and Fix

- Model Prototyping

- Model Incremental

- Model Spiral

- Model Waterfall / SDLC (Software Develop-ment Live Cycle) 
Pengembangan sistem software umumnya menggunakan metodologi System Development Live Cycle (SLDC) yang artinya siklus hidup pengembangan sistem. Dari kelima model metodologi di atas, model waterfall adalah model pengembangan sistem yang paling banyak digunakan ${ }^{3)}$. Model ini memiliki tahapan :

- $\quad$ Scope and Objective

- Feasibility Study

- System Analysis

- System Design

- $\quad$ Detailed Design

- Implementation

- Changeover

- Evaluation \& Maintenance

\section{I.3. Tujuan dan Sasaran}

Tujuan dari kegiatan ini adalah mengembangkan perangkat lunak pengelolaan data untuk monitoring paramater lingkungan suatu TPA. Sedangkan sasaran akhir kegiatan adalah diperolehnya perangkat lunak pengolahan yang dapat mengelola data parameter gas, temperatur, kelembaban dan debit gas di setiap lapisan sampah yang ada di skala.

\subsection{Lingkup Kegiatan}

Ruang lingkup kegiatan yang dilaksanakan dalam melakukan pengembangan perangkat lunak ini adalah :

- Penggalian kebutuhan pengguna, dilakukan dengan interview terhadap pengguna berkaitan dengan fitur perangkat lunak yang dibutuhkan.

- Merancang struktur database dan user interface yang dapat mewakili kebutuhan pengguna dan fitur perangkat lunak yang akan dikembangkan.

- Membangun perangkat lunak sesuai disain yang telah dirancang sesuai kebutuhan pengguna.

Menguji pengoperasian perangkat lunak.

\subsection{Metodologi Pelaksanaan}

Metodologi pelaksanaan kegiatan ini dilaksanakan dalam tahapan seperti pada gambar 1, yaitu :

- Merencanakan tujuan utama dari pembuatan perangkat lunak ini.

- Mendefinisikan jangkauan dan batasan aplikasi database, serta siapa pengguna utamanya.

- $\quad$ Proses pengumpulan dan analisa data informasi yang dibutuhkan.

- Membuat sebuah rancangan database yang mendukung semua kegiatan.

- Memilih Sistem Manajemen Database yang cocok untuk menjalankan aplikasi database.

- Merancang GUI user interface dan program aplikasi yang akan digunakan serta untuk memproses database.

- Membangun prototipe program aplikasi database

- $\quad$ Proses running dan pengujian program aplikasi secara terus menerus untuk menemukan kesalahan.

- Mengimplementasikan program database pada kondisi sebenarnya.

Proses pemantauan dan pemeliharaan program database yang sudah terpasang. 


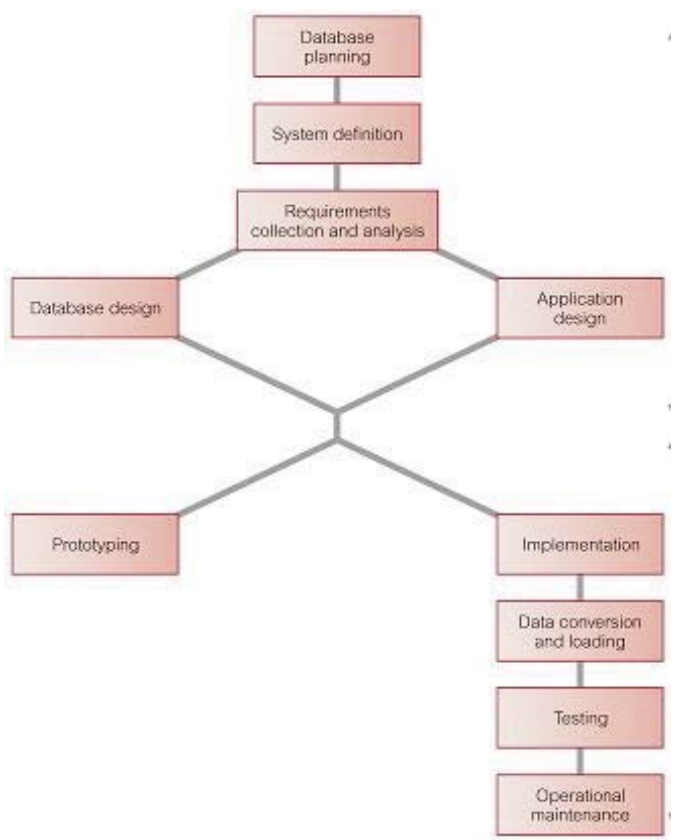

Gambar 1. Siklus Pembuatan Aplikasi Database

\section{PEMBAHASAN}

\subsection{Perancangan Sistem Basis Data}

Pengembangan sistem basis data sangat tergantung dengan kebutuhan pengguna sistem, karena hal ini sangat terkait dengan kebutuhan akan penyajian informasi dalam format tertentu. Perancangan database dikembangkan melalui beberapa proses tahapan, yaitu :

1. Survei pengumpulan data. Data yang dikumpulkan meliputi peraturan perundangan dan referensi lain yang berkaitan dengan pembangunan sebuah TPA, contoh data-data hasil pengukuran secara manual dan dokumentasi contoh pelaporan data.

2. Interview kebutuhan pengguna. Interview dilakukan kepada pengguna yang berhubungan langsung dengan kegiatan penelitian di TPA. Interview ini dilakukan untuk mendapatkan kepastian mengenai penggunaan parameter pengukuran dan contohcontoh format penulisan data.
3. Analisa sistem data dan pelaporan data. Data-data dan contoh-contoh pelaporan data yang telah dikumpulkan dianalisa untuk menentukan entitas data pemantauan kinerja TPA. Dari entitas yang dihasilkan ditentukan pula parameter data yang akan digunakan.

Dari hasil survei dan interview terhadap kebutuhan pengguna khususnya peneliti lingkungan yang melakukan penelitian mengenai kinerja suatu TPA dapat disimpulkan bahwa dalam satu TPA bisa terdapat lebih dari satu buah titik pantau yang digunakan untuk memantau kualitas dan kuantitas gas yang dihasilkan oleh TPA tersebut.

Entitas yang didapat dari kegiatan monitoring gas di TPA ini adalah : (1). Entitas titik pengamatan (sumur pantau), dan (2). Entitas data pemantauan (paramater gas). Kedua entitas ini memiliki relasi/hubungan 'pengukuran' yang dilakukan setiap interval waktu tertentu (tanggal, jam). Masing-masing entitas dan relasi tersebut (Gambar 2) memiliki atribut informasi sebagai berikut:

1. Entitas Titik Pengamatan (Sumur Pantau)

- ID Sumur

- Nama Sumur

- Koordinat lokasi (Lintang, Bujur)

- Kontak person

- Keterangan lain

2. Entitas Data Pemantauan (Parameter Gas)

- $\mathrm{CH}_{4}$ / gas metan

- $\mathrm{CO}_{2}$ / gas karbon dioksida

- $\mathrm{H}_{2} \mathrm{~S} /$ gas hidrogen sulfida

- $\mathrm{O}^{2} /$ gas oksigen

- Suhu / temperatur

- Kelembaban

- Debit flow gas 
3. Entitas Pengukuran

- Tanggal pengukuran

- Jam pengukuran

Sumur
Pantau
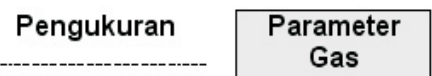

Gambar 2. Relasi Pada Entitas Monitoring TPA

Selain entitas di atas, terdapat entitias tambahan, yakni pengguna yang memiliki atribut informasi sebagai berikut :

Tabel 2. Tabel 1. Data Sumur Pantau
4. Entitas Pengguna

- ID Pengguna

- Kode Akses/Nama User

- Nama Lengkap

- Nomor Telepon

- Password

- Jabatan/Otoritas Akses

\subsection{Rancangan Tabel Data}

Dari hasil penjabaran beberapa entitas di atas, maka dapat dirancangan tabel-tabel pemantauan kinerja TPA seperti contoh di bawah ini:

\begin{tabular}{|l|l|l|}
\hline \multicolumn{1}{|c|}{ Field Parameter } & Tipe Data & \multicolumn{1}{c|}{ Keterangan } \\
\hline IDSumur ${ }^{*}$ & Text & Nomor Identifikasi Sumur Pantau \\
\hline NamaSumur & Text & Nama Sumur Pantau \\
\hline KontakPerson & Text & Nama Penanggung Jawab Sumur Pantau \\
\hline LintangDerajat & Integer & Posisi Koordinat Lintang Derajat \\
\hline LintangMenit & Integer & Posisi Koordinat Lintang Menit \\
\hline LintangDetik & Integer & Posisi Koordinat Lintang Detik \\
\hline BujurDerajat & Integer & Posisi Koordinat Bujur Derajat \\
\hline BujurMenit & Integer & Posisi Koordinat Bujur Menit \\
\hline BujurDetik & Integer & Posisi Koordinat Bujur Detik \\
\hline Keterangan & Text & Keterangan Lain Tentang Sumur Pantau \\
\hline
\end{tabular}

* Primary Key

Tabel 2. Data Pengukuran

\begin{tabular}{|c|c|c|}
\hline Field Parameter & Tipe Data & Keterangan \\
\hline IDSumur* & Text & Nomor Identifikasi Sumur Pantau \\
\hline Tanggal * & Date & Tanggal Pengukuran \\
\hline Jam * & Time & Waktu Pengukuran \\
\hline $\mathrm{CH}_{4}$ & Double & Kandungan Gas $\mathrm{CH}_{4}$ \\
\hline $\mathrm{CO}_{2}$ & Double & Kandungan $\mathrm{CO}_{2}$ \\
\hline $\mathrm{H} 2 \mathrm{~S}$ & Double & Kandungan Gas Hidrogen Sulfida \\
\hline $\mathrm{O}^{2}$ & Double & Kandungan Gas $\mathrm{O}^{2}$ \\
\hline Suhu & Double & Temperatur Sampah \\
\hline Kelembaban & Double & Kelembaban Sampah \\
\hline Debit & Double & Debit / flow gas \\
\hline
\end{tabular}

* Primary Key 
Tabel 3. Data Pengguna

\begin{tabular}{|l|l|l|}
\hline \multicolumn{1}{|c|}{ Field Parameter } & \multicolumn{1}{c|}{ Tipe Data } & \multicolumn{1}{c|}{ Keterangan } \\
\hline IDUser ${ }^{*}$ & Text & Nomor Identifikasi Pengguna \\
\hline NamaUser & Text & Kode Login Pengguna \\
\hline NamaLengkap & Text & Nama Lengkap Pengguna \\
\hline NoTelepon & Text & No HP Data Logger \\
\hline Password & Text & Kata Kunci Pengguna \\
\hline Otoritas & Text & Otoritas Akses Pengguna \\
\hline
\end{tabular}

* Primary Key

Tabel berikut adalah nama field data, format data dan contoh data yang akan dikelola oleh tabel pengukuran.

Tabel 4. Format Data Tanggal, Jam dan Parameter Ukur Lain

\begin{tabular}{|l|l|l|}
\hline \multicolumn{1}{|c|}{ Data } & \multicolumn{1}{c|}{ Format } & \multicolumn{1}{c|}{ Contoh } \\
\hline Tanggal & DD/MM/YYYY & $01 / 07 / 2007$ \\
\hline Waktu & $\mathrm{HH}: \mathrm{MM}: \mathrm{SS}$ & $09: 15: 05$ \\
\hline $\mathrm{CH}_{4}$ & double & 12,25 \\
\hline $\mathrm{CO}_{2}$ & double & 21,35 \\
\hline $\mathrm{H}_{2} \mathrm{~S}$ & double & 15,40 \\
\hline $\mathrm{O}_{2}$ & double & 10,15 \\
\hline Suhu & double & 13,01 \\
\hline Kelembaban & double & 24,21 \\
\hline Debit & double & 9,13 \\
\hline
\end{tabular}

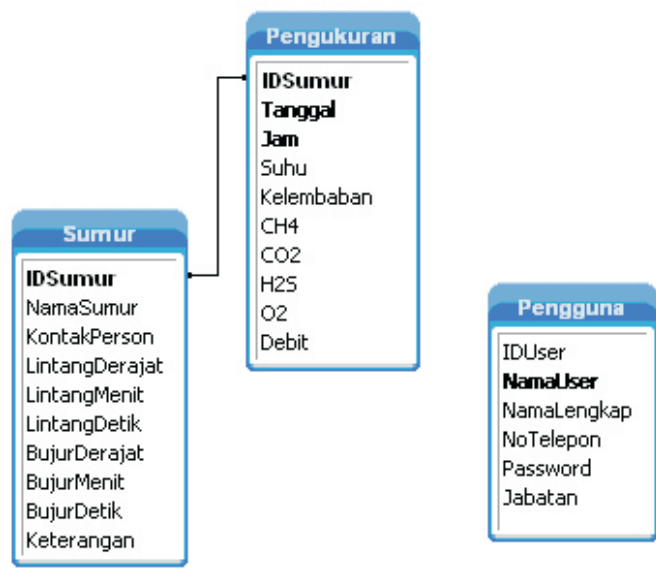

Gambar 3. Rancangan RDMS

\subsection{Disain Tabel Kerja (View/Query)}

Untuk keperluan manipulasi data pada sistem database kinerja TPA, perlu didefinisikan juga beberapa tabel kerja (view/query) yang merupakan gabungan dari beberapa tabel inti yang memiliki relasi. Tabel-tabel kerja atau query tersebut didefinisikan menggunakan bahasa query terstruktur SQL (Structured Query Language) yang merupakan bahasa standar pemrograman untuk pengembangan sistem database. Beberapa tabel kerja / query yang dihasilkan antara lain :

Tabel 5. Query Parameter

\begin{tabular}{|c|c|}
\hline Tabel View/Query & Tabel \\
\hline \multirow[t]{2}{*}{ Monitoring } & - SumurPantau \\
\hline & - $\quad$ Pengukuran \\
\hline \multirow[t]{2}{*}{ Data } & - SumurPantau \\
\hline & - $\quad$ Pengukuran \\
\hline JumlahData1 & - $\quad$ Monitoring \\
\hline JumlahData2 & - JumlahData1 \\
\hline
\end{tabular}

Data Manipulation Language (DML) untuk masing-masing query adalah sebagai berikut :

\section{DML Query Monitoring :}

SELECT IDPantau, NamaPantau, KontakPerson, Keterangan, Tanggal, Jam, Suhu, Kelembaban, $\mathrm{CH}_{4}, \mathrm{CO}_{2}, \mathrm{H}_{2} \mathrm{~S}, \mathrm{O}^{2}$, Debit FROM Sumur, Pengukuran

WHERE Sumur.IDPantau = Pengukuran . IDPantau

ORDER BY IDPantau, Tanggal, Jam; 


\section{DML Query Data :}

SELECT IDPantau, NamaPantau, Tanggal, Jam, Suhu, Kelembaban, $\mathrm{CH}_{4}, \mathrm{CO}_{2}, \mathrm{H}_{2} \mathrm{~S}$, $\mathrm{O}^{2}$, Debit, KontakPerson, LintangDerajat, LintangMenit, LintangDetik, BujurDerajat, BujurMenit, BujurDetik, Keterangan

FROM Stasiun, Pengukuran

WHERE Stasiun.IDPantau $=$ Pengukuran. IDPantau

ORDER BY IDPantau, Tanggal, Jam;

\section{DML Query JumlahData1 :}

SELECT IDPantau AS IDPantau, Tanggal, Count(Jam) AS JmlJam, NamaPantau AS NamaPantau, Avg(Suhu) AS Rata2Suhu, Avg(Kelembaban) AS Rata2Lembab, Avg $\left(\mathrm{CH}_{4}\right)$ AS Rata2 $\mathrm{CH}_{4}, \operatorname{Avg}\left(\mathrm{CO}_{2}\right)$ AS Rata $2 \mathrm{CO}_{2}$, $\mathrm{Avg}\left(\mathrm{O}^{2}\right) \mathrm{AS}$ Rata2O2, $\mathrm{Avg}\left(\mathrm{H}_{2} \mathrm{~S}\right)$ AS Rata2 $\mathrm{H}_{2} \mathrm{~S}$, Avg(Debit) AS Rata2Debit

FROM Monitoring

GROUP BY IDPantau, Tanggal, NamaPantau ORDER BY IDPantau, NamaPantau;

\section{DML Query JumlahData2 :}

SELECT IDPantau AS IDPantau, NamaPantau AS NamaPantau, Count(Tanggal) AS JmITgl, Sum(JmlJam) AS JmlJam, Avg $\left(\operatorname{Rata} 2 \mathrm{CH}_{4}\right)$ AS Rata2 $\mathrm{CH}_{4}$, Avg $\left(\right.$ Rata2 $\left.\mathrm{CO}_{2}\right)$ AS Rata2 $\mathrm{CO}_{2}$, Avg(Rata2 $\left.\mathrm{H}_{2} \mathrm{~S}\right) \mathrm{AS}$ Rata2 $\mathrm{H}_{2} \mathrm{~S}$, Avg(Rata2O ${ }^{2}$ ) AS Rata2O ${ }^{2}$, Avg(Rata2Suhu) AS Rata2Suhu, Avg(Rata2Lembab) AS Rata2Lembab, Avg(Rata2Debit) AS Rata2Debit

FROM JumlahData1

GROUP BY IDPantau, NamaPantau

ORDER BY IDPantau;

Selain keempat tabel kerja di atas, untuk menampilkan data monitoring kinerja TPA yang telah diukur ke dalam tampilan grafik, perlu didefinisikan DML sebagai berikut :

SELECT Jam, \&Parameter\& INTO TempTable

FROM Pengukuran

WHERE IDSumur $=$ \&IDSumur2\& AND Tanggal $=$ \&Tglukur \& AND Jam BETWEEN \&DariJam\& AND \&SampaiJam\&

ORDER BY Jam;
Adapun arti dari masing-masing variabel pada DML di atas adalah :

- \&Parameter\& : field $\mathrm{CH}_{3}, \mathrm{CO}_{2}, \mathrm{H}_{2} \mathrm{~S}$, $\mathrm{CO}_{2}$, Suhu, Kelembaban, Debit

- $\quad$ \&IDStasiun2 : ID stasiun monitoring

- $\quad$ \&TglUkur\&: tanggal pengukuran

- \&DariJam\&: jam mulai pengukuran

- \&SampaiJam\&: jam akhir pengukuran

\subsection{Perancangan User Interface Database}

Perancangan user interface perangkat lunak untuk database monitoring TPA dilakukan dengan membuat model-model form pengisian data sesuai dengan tabel data dan tabel kerja yang ada. Selain itu juga disusun berbagai bentuk format laporan data pengukuran untuk menampilkan data monitoring TPA di setiap sumur pantau.

Rancangan awal disusun dengan membuat prototipe software yang didasarkan pada hasil rancangan database terstruktur. Rancangan awal ini dapat diubah kembali sesuai dengan kebutuhan pengguna di lapangan. Rancangan sistem pengoperasian user interface yang dikembangkan dapat dilihat seperti pada gambar 4 .

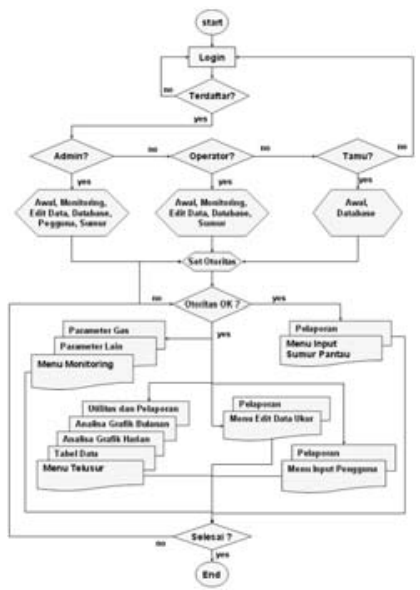

Gambar 4. Diagram Alir Proses Pengoperasian Perangkat Lunak 
Adapun rancangan struktur direktori instalasinya adalah seperti pada gambar 5 berikut.

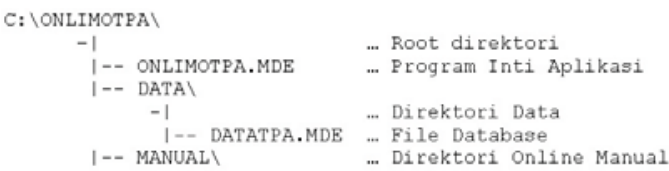

Gambar 5. Struktur Direktori Instalasi

\subsection{Perancangan Modul User Interface}

Sistem perangkat lunak yang dikembangkan terdiri dari modul pengisian data stasiun, modul editing data pengukuran online dan manual, modul penelusuran data, serta modul pelaporan data yang terdiri dari laporan ringkas, laporan rinci, laporan lengkap, dan laporan satuan data. Masingmasing modul dirancang sedemikian rupa agar dapat dengan mudah digunakan oleh pengguna sistem ini.

\subsubsection{Modul Menu Utama}

Modul ini akan muncul pertama kali saat pengguna berhasil login ke dalam sistem dengan otoritas aksesnya. Menu utama berisi ikon untuk mengaktifkan modul lain di dalamnya, yakni :

- Ikon Awal, untuk kembali ke tampilan awal program aplikasi.

- Ikon Monitoring, untuk memantau data pengukuran secara online.

- Ikon Edit Data, untuk menyunting data pengukuran online.

- Ikon Database, digunakan untuk menelusuri data pengukuran online.

- Ikon Pengguna, untuk mengelola login dan password pengguna.

- Ikon Sumur, untuk mengelola data fisik sumur pantau.

- Ikon Selesai, untuk keluar atau selesai dari program aplikasi ini.

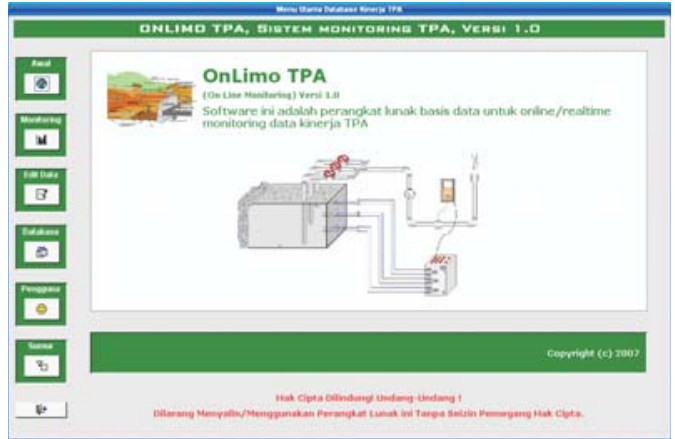

Gambar 6. Rancangan Modul Menu Utama

\subsubsection{Modul Monitoring}

Modul ini digunakan untuk memantau data yang sedang dikirim oleh data logger ke dalam sistem penerimaan data di pusat data, sehingga proses monitoring dapat dilakukan secara online dan real time. Modul monitoring yang disediakan terbagi ke dalam tiga jenis pilihan monitoring, yaitu monitoring parameter gas, monitoring paramater lain dan monitoring satu parameter ukur.

Pada monitoring parameter gas, komputer hanya menampilkan ke layar monitor hasil pengukuran untuk empat gas, yaitu $\mathrm{CH}_{4}, \mathrm{CO}_{2}, \mathrm{H}_{2} \mathrm{~S}$, dan $\mathrm{O}^{2}$. Pada monitoring parameter lain, komputer akan menampilkan ke layar monitor hasil pengukuran terhadap parameter lain selain gas, yaitu temperatur, kelembaban dan debit flow gas secara keseluruhan. Sedangkan pada window satu parameter komputer akan menampilkan salah satu hasil pengukuran ketujuh parameter ukur di atas sesuai pilihan pengguna ke dalam tampilan yang lebih besar.

Melalui ketiga jenis tampilan window pada menu monitoring di atas pengguna dapat menentukan sendiri interval waktu pembaharuan data dalam satuan detik misalnya 900 detik, 1800 detik atau 3600 detik. Jika tidak ditentukan secara otomatis komputer akan membaharui tampilan data setiap 90 detik. Makin banyak data yang masuk makin rapat grafik yang akan ditampilkan ke layar monitor. Selain grafik, komputer juga akan menampilkan angka 
hasil pengukurannya di atas gambar titik pada masing-masing grafiknya.

Gambar 7 berikut adalah rancangan modul monitoring untuk paramater gas sedangkan gambar 8 adalah rancangan modul monitoring untuk parameter temperatur, debit gas dan kelembaban.

\subsubsection{Modul Edit Data}

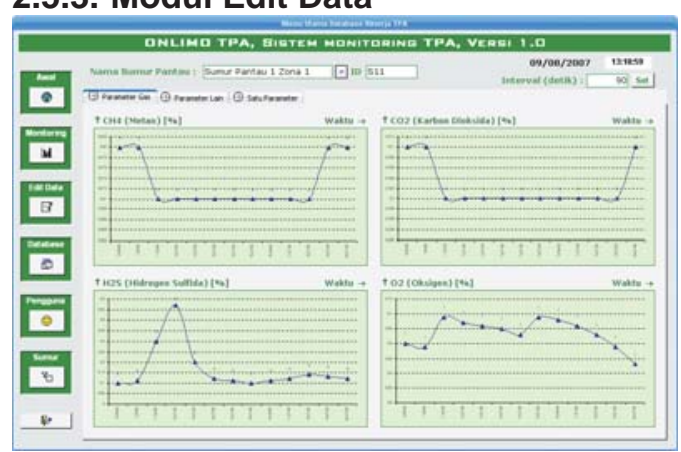

Gambar 7. Rancangan Modul Monitoring Tab Control Parameter Gas

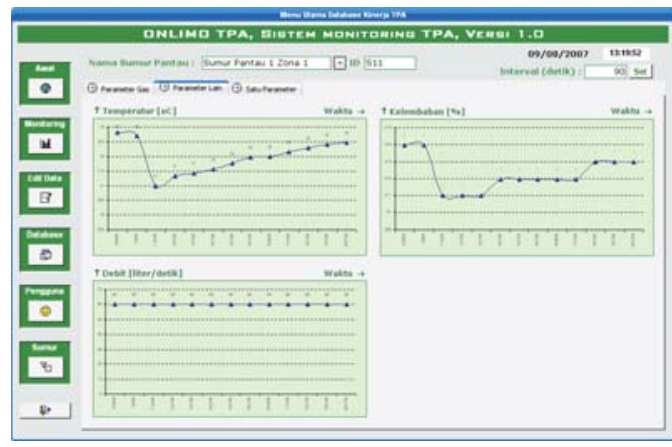

Gambar 8. Rancangan Modul Monitoring Tab Control Parameter Lain (Temperatur, Kelembaban dan Debit)

Modul editing data dibuat untuk menyunting data-data hasil pengukuran secara online. Secara teoritis data hasil pengukuran tidak perlu dsunting, namun jika terpaksa diperlukan maka modul ini dapat membantu proses editing tersebut. Contoh data yang perlu disunting misalnya jika terdapat data dengan nilai minus, dimana nilai minus ini merupakan tanda-tanda bahwa sensor perlu dikalibrasi kembali. Selain data pengukuran dapat disunting pula data lokasi sumur pantau untuk masing-masing lokasi pemantauan.

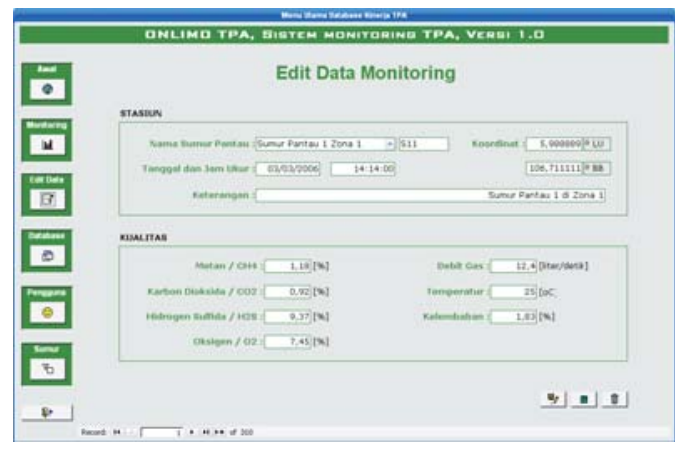

Gambar 9. Rancangan Modul Edit Data

Pada gambar di atas pengguna dapat menyunting parameter pengukuran gas $\mathrm{CH} 4, \mathrm{CO}_{2}, \mathrm{H}_{2} \mathrm{~S}, \mathrm{O}^{2}$, Temperatur, Kelembaban dan Debit gas. Modul ini khusus digunakan hanya untuk menyunting ke tujuh parameter data di atas, untuk data sumur pantau jika diperlukan sebaiknya disunting melalui modul sumur pantau. Jika perubahan data telah dilakukan pengguna dapat menekan ikon "save" untuk menyimpan data.

\subsubsection{Modul Database}

Modul database digunakan sebagai modul penelusuran data. Modul ini terdiri dari empat buah tab control yang berisi fitur berbeda-beda, yaitu :

- Tab Control Tabel Data

- Tab Control Analisa Grafik Harian

- Tab Control Grafik Analisa Bulanan

- Tab Control Utilitas dan Pelaporan

Untuk menampilkan data yang diukur oleh masing-masing sumur pantau, pengguna pengguna harus memilih salah satu dari nama sumur pantau yang ada. Setelah salah satu nama sumur pantau dipilih, komputer akan menampilkan datadata pengukurannya yang sudah tersimpan di dalam database.

Pada Tab Contro/Tabel Data, komputer akan menampilkan data pengukuran yang sesuai dengan ID sumur pantau yang telah 


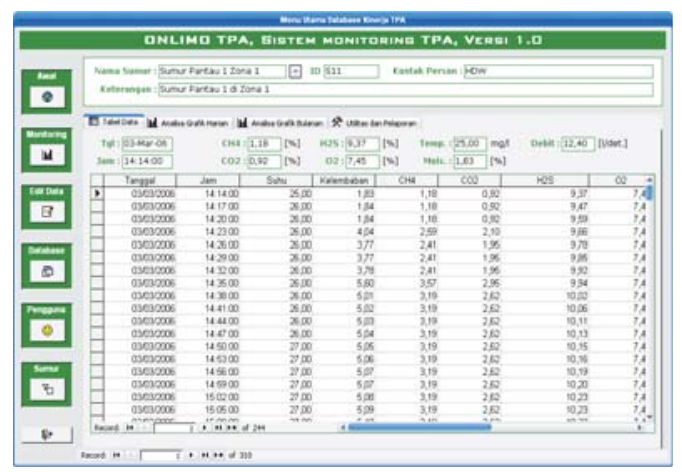

Gambar 10. Rancangan Modul Database Tab Control Tabel Data

dipilih. Pengguna dapat menggunakan ikon navigasi data untuk memindahkan kursor dari data yang satu ke data yang lain. Pada modul ini pengguna tidak dapat menyunting data yang ditampilkan.

Tab Control berikutnya adalah Anallisa Grafik Harian. Pada Tab Control ini untuk menampilkan grafik harian, pengguna harus memasukkan data-data : tanggal pengukuran, waktu pengukuran, lokasi pengukuran dan parameter ukur yang akan ditampilkan grafiknya.

Setelah pengguna memasuk-kan query data yang dibutuhkan, komputer akan secara otomatis memanggil data yang sesuai dengan kelompok data yang dimaksud dan menampilkan data angka dan grafiknya ke layar monitor. Query data Tahun, Bulan, Tanggal, Jam Mulai dan Jam Akhir dapat berubah-ubah sesuai dengan data sumur pantau yang akan dipilih.

Setiap penggantian query parameter ukur data, komputer secara otomatis akan memperbaharui grafik data. Namun jika yang diubah adalah query Tahun, Bulan, Tanggal, Jam Mulai dan Jam Akhir pengguna harus menekan ikon 'Reload Grafik' untuk memperbaharui tampilan grafik. Grafik yang ditampilkan akan semakin rapat jika data yang ada semakin banyak. Jika terlalu rapat pengguna dapat mengubah query data Jam Mulai dan Jam Akhir pengukuran.
Tab Control berikutnya adalah Analisa Grafik Bulanan. Pada tab control

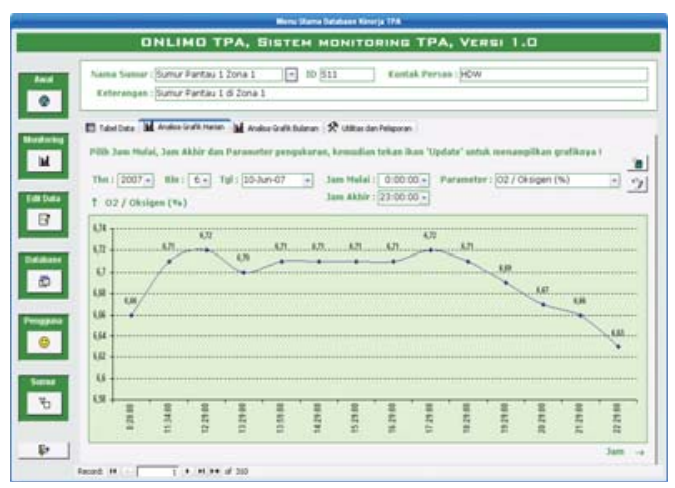

Gambar 11. Rancangan Modul Database Tab Control Analisa Grafik Harian

ini pengguna harus memasukkan query data bulan pengukuran dan parameter ukur yang akan ditampilkan grafiknya. Setiap penggantian query parameter, komputer secara otomatis akan memperbaharui grafik data, tetapi jika yang diubah adalah query data Bulan pengguna harus menekan ikon 'Reload Grafik' untuk memperbaharui tampilan grafik.

Tab Control terakhir dari Modul Database adalah Tab Control Utilitas dan Pelaporan. Pada tab control ini pengguna dapat menampilkan berbagai format laporan data monitoring, data sumur pantau dan data pengguna. Selain itu tab control ini berisi utilitas untuk mengekspor data ke dalam format MS Excel. Format laporan yang disediakan adalah : Laporan Ringkat, Laporan Rinci, Laporan Lengkap dan Laporan Satuan Data. 


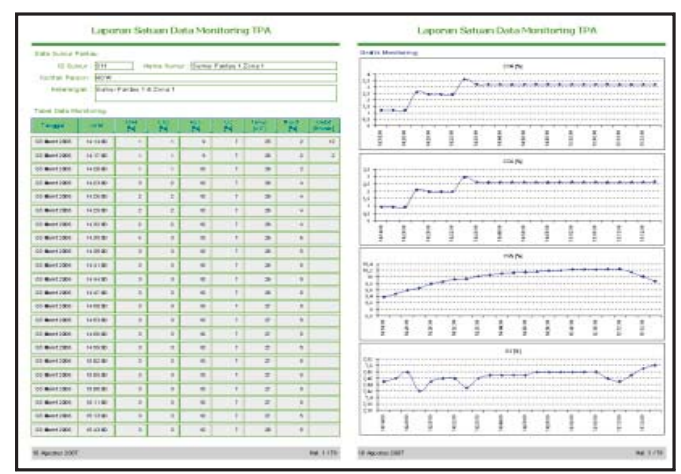

Gambar 12. Laporan Satuan Data Monitoring

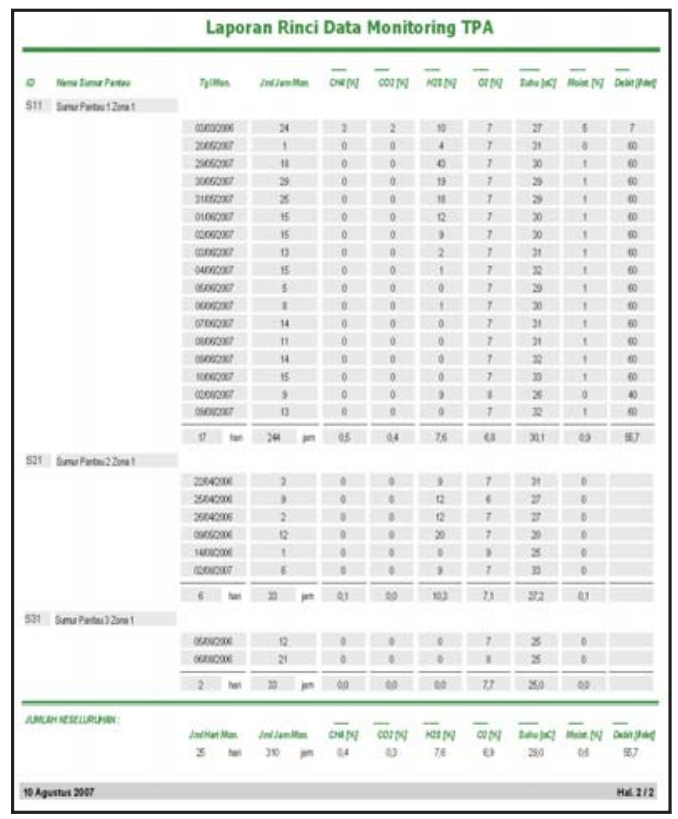

Gambar 13. Laporan Rinci Data Monitoring

\subsubsection{Modul Sumur}

Modul sumur digunakan untuk menyunting dan menelusuri informasi data umum mengenai lokasi sumur pantau. Pada modul ini pengguna dapat menyunting data nama sumur pantau, kontak person / orang yang bertanggung jawab terhadap sumur pantau ini, koordinat lintang dan bujur dalam satuan derajat, menit dan detik serta keterangan lain yang berkaitan dengan sumur pantau ini.
Modul ini akan menampilkan data sumur pantau dalam dua bentuk format, yaitu : 1). Bagian atas merupakan data satuan sumur pantau dan 2). Bagian bawah merupakan tabel daftar sumur pantau. Untuk memilih data satuan pada bagian atas pengguna dapat menggunakan ikon navigasi yang berada di paling bawah window, sedangkan untuk memilih data pada tabel daftar sumur pantau menggunakan ikon navigasi di atasnya.

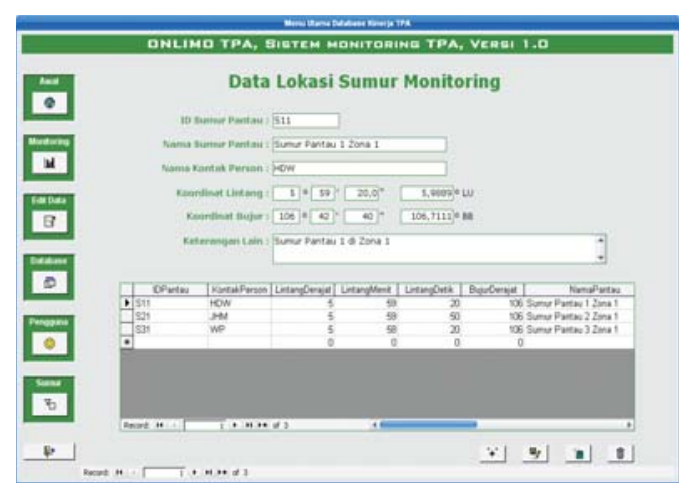

Gambar 14. Rancangan Modul Sumur

\subsubsection{Modul Pengguna}

Modul ini digunakan untuk mendaftarkan pengguna baru atau menyunting data pengguna perangkat lunak. Modul ini hanya dapat dibuka oleh pengguna dengan otoritas akses sebagai administrator. Modul ini terdiri dari dua bagian, yaitu form isian data pengguna dan tabel data pengguna. Untuk mendaftarkan pengguna baru administrator harus menuliskan data nama login, nomor telepon pengguna, nama lengkap, password dan jabatan pengguna.

Jabatan yang dimaksud di sini adalah posisi atau otoritas akses pengguna dalam program aplikasi ini. Administrator dapat memilih salah satu dari pilihan otoritas akses 'Administrator, Operator atau Tamu'. Password yang diketikkan oleh administrator secara otomatis akan ditampilkan dalam huruf bintangbintang seperti '********) supaya password tersebut tidak mudah dibaca oleh orang lain pada saat diketikkan ke layar komputer. 


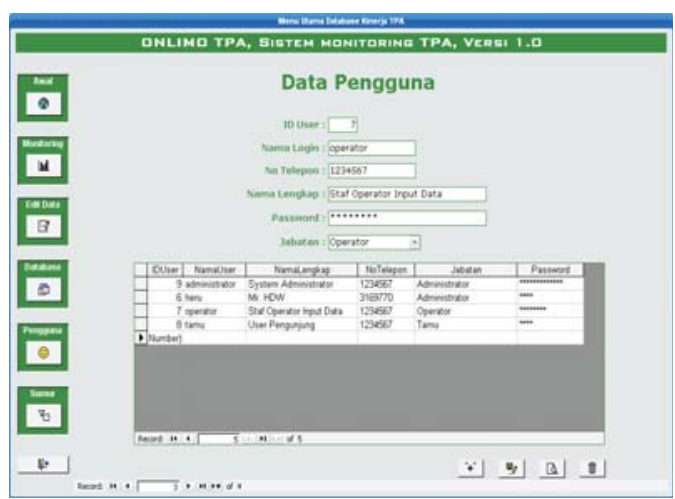

Gambar 15. Window Pengguna

Untuk memilih data pengguna pada form isian pengguna administrator dapat memakai ikon navigasi yang berada di bagian bawah window dan untuk memilih data pengguna dalam tabel pengguna administrator dapat memilih ikon navigasi yang berada tepat di atasnya. Untuk mengamankan data, setiap pengguna dapat diberikan otoritas akses yang berbeda-beda. Otoritas ini yang membedakan akses antara pengguna yang satu dengan pengguna yang lain. Otoritas aksesnya terdiri dari tiga jenis, yaitu :

- Administrator : memiliki semua otoritas untuk mengelola seluruh sistem.

- Operator : memiliki otoritas memasukkan dan menyunting data, menelusuri dan melihat atau mencetak laporan data.

- Tamu : hanya memiliki otoritas menelusuri data.

Tabel 6. Kategori Pengguna dan Otoritas Akses

\begin{tabular}{|l|c|c|c|c|}
\hline $\begin{array}{c}\text { Pengguna } \\
\text { Sistem }\end{array}$ & $\begin{array}{c}\text { Input } \\
\text { Data }\end{array}$ & $\begin{array}{c}\text { Lihat } \\
\text { Data }\end{array}$ & $\begin{array}{c}\text { Laporan } \\
\text { Data }\end{array}$ & $\begin{array}{c}\text { Sistem } \\
\text { Admin }\end{array}$ \\
\hline Administrator & $\checkmark$ & $\checkmark$ & $\checkmark$ & $\checkmark$ \\
\hline Operator & $\checkmark$ & $\checkmark$ & $\checkmark$ & $X$ \\
\hline Tamu & $\overline{1}$ & $\checkmark$ & $\mathrm{d}$ & $\mathrm{X}$ \\
\hline
\end{tabular}

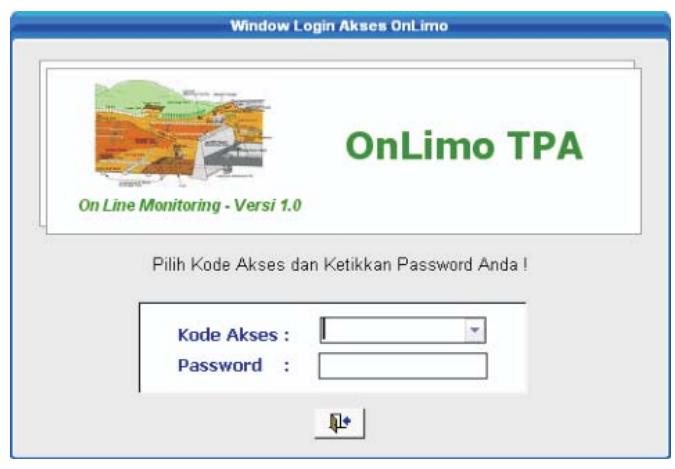

Gambar 16. Window Login Akses ke Software

Pengguna yang sudah terdaftar secara otomatis kode loginnya akan muncul pada daftar kode akses dalam window login gambar di bawah ini. Sehingga user cukup memilih kode akses yang sesuai dan hanya mengetikkan password dengan benar.

Otoritas akses yang diberikan administrator kepada pengguna berpengaruh terhadap status beberapa ikon pada modul menu utama. Ikon-ikon ini akan aktif atau pasif sesuai otoritas pengguna yang sedang login. Ikon aktif artinya ikon ini dapat diklik untuk mengaktifkan modul yang ada di dalamnya, sedangkan ikon pasif artinya ikon ini tidak dapat diklik dan pengguna tersebut tidak dapat mengaktifkan modul yang dimaksud.

\subsubsection{Modul Pendukung}

Untuk melengkapi kebutuhan pengguna dalam mengoperasikan program aplikasi ini telah disiapkan modul-modul pendukung seperti :

- Modul Pelaporan. Modul ini berisi rancangan berbagai bentuk dokumentasi pelaporan, antara lain : laporan ringkas, laporan rinci, laporan lengkap dan laporan satuan data.

- Modul Petunjuk Pemakaian. Modul ini merupakan dokumentasi elektronik petunjuk pengoperasian sistem software secara keseluruhan. 


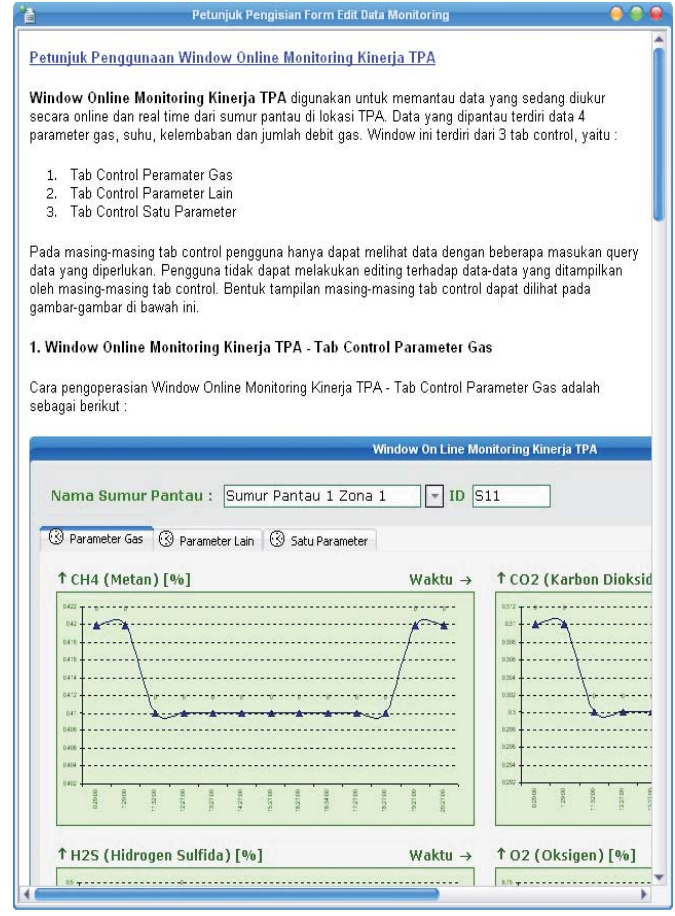

Gambar 17. Window Petunjuk Pemakaian

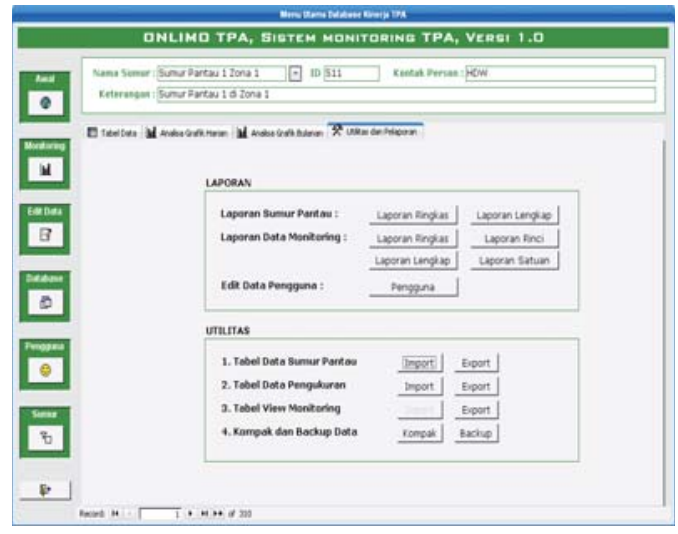

Gambar 18. Rancangan Modul Database Tab Control Utilitas dan Pelaporan

\section{KESIMPULAN DAN SARAN}

\subsection{Kesimpulan}

Beberapa kesimpulan yang dapat diambil dari proses pengembangan database kinerja TPA adalah sebagai berikut :
1. Software ini dirancang agar dapat melakukan sinkronisasi data ke perangkat data logger yang bertugas mengumpulkan data dari lokasi pengamatan di TPA.

2. Modul yang disediakan terdiri modul untuk input / editing data, modul penelusuran data, modul pelaporan dan modul online manual yang semuanya dibuat untuk kemudahan pengguna.

3. Untuk melindungi perangkat lunak dan kemudahan prosedur instalasinya, software ini dapat didistribusikan dalam bentuk paket software yang terkompresi dengan dilengkapi password instalasi.

\subsection{Saran}

1. Untuk keperluan uji coba (software testing) khususnya pengujian pada modul monitoring disarankan agar dibuat program data generator yang dapat menghasilkan data-data dummy secara otomatis setiap interval waktu yang telah ditentukan. Program data generator ini diperlukan untuk menguji apakah program database yang dibuat dapat meng-update datanya secara otomatis jika terjadi penambahan data.

2. Agar program database dapat bekerja sinergi dengan program kendali data logger, maka disarankan pula agar program SMS gateway pada logger memakai file sharing "DataPengukuran.txt" sebagai file data bersama antara kedua program tersebt. File data ini bertugas sebagai perantara penerimaan data, dimana data pengukuran yang dikirimkan oleh data logger disimpan dalam file ini terlebih dahulu, kemudian secara berkala file ini dibaca oleh program database untuk dilakukan sinkronisasi data. 


\section{DAFTAR PUSTAKA}

1. 2008. Undang-Undang No. 18 Tahun 2008 Tentang Pengelolaan Sampah, Setnek - RI, Jakarta

2. 2006. Laporan Akhir Kajian Pengelolaan Leachate dan Gas Di TPA, PTL-BPPT, Jakarta

3. Curtis, G., 1995. Bussiness Information System $2^{\text {nd }}$ Edition. Wokingham, England: Addison Wesley
4. 2008. Criteria for Solid Waste Disposal Facilities-A Guide for Owners / Operators: Solid Waste and Emergency Response, US EPA.

5. ____, 2008. Pengelolaan Persampahan, Balai Lingkungan Permukiman. 